\title{
A Case of Familial Pulmonary Mycobacterium avium Complex Disease
}

\author{
Masashi Matsuyama ${ }^{1}$, Yukiko Miura ${ }^{1}$, Takumi Kiwamoto ${ }^{1}$, Ataru Moriya ${ }^{1}$, \\ Nariaki Kokuho ${ }^{1}$, Kei Shimizu ${ }^{1}$, Shigeo Otsuka ${ }^{1}$, Minako Hijikata ${ }^{2}$, \\ Naoto Keicho $^{2}$, Kenji Hayashihara ${ }^{1}$ and Takefumi Saito ${ }^{1}$
}

\begin{abstract}
We report one Japanese familial line in which there were three pulmonary MAC patients and one suspected patient over two generations, most of whom were diagnosed with the nodular/bronchiectatic type. In all patients, life circumstances and bacterial strains differed at the time of diagnosis. This suggests that the genes thought to affect patient susceptibility to pulmonary MAC disease may be involved in this family line. Comprehensive genotypic analysis of the CFTR gene, HLA typing, and analysis of the NRAMP1 polymorphisms were performed in seven members of this family. The results suggest that female sex and menopause might be associated with onset of pulmonary MAC of the nodular/bronchiectatic type, and HLA-A26 antigen and diabetes mellitus might be involved in disease exacerbations.
\end{abstract}

Key words: familial pulmonary Mycobacterium avium complex disease, HLA-A26 antigen, menopause, CFTR, NRAMP1

(Inter Med 49: 949-953, 2010)

(DOI: 10.2169/internalmedicine.49.3023)

\section{Introduction}

Mycobacterium avium complex (MAC) lung disease is becoming increasingly prevalent, particularly the nodular/bronchiectatic type in patients with no pre-existing structural lung disease. Genetic defects have been suggested in familial cases; the sibling risk for nodular/bronchiectatic type pulmonary MAC is much higher than the population prevalence $(1,2)$.

Familial pulmonary MAC disease reports are very rare $(2,3)$. Most previous reports of pulmonary MAC disease susceptibility genes have been case-control studies of unrelated subjects, looking for polymorphisms in $H L A$, CFTR, and NRAMP1 (4-11). To the best of our knowledge, this is the first report of familial pulmonary MAC disease with comprehensive genotypic analysis of the CFTR gene, HLA typing, and analysis of the NRAMP1 polymorphisms. The present family included three patients and one sus- pected patient over two generations, most of whom had nodular/bronchiectatic type pulmonary MAC. Since each patient's life circumstances and bacterial strains differed at the time of pulmonary MAC diagnosis, genes or unknown factors affecting susceptibility to pulmonary MAC disease might have been involved. Thus, the clinical manifestations and genetic polymorphisms of the pulmonary MAC disease patients and healthy family members were analyzed to identify factors implicated in the development and exacerbation of pulmonary MAC disease.

Abbreviations: NRAMP1: natural resistance-associated macrophage protein, CFTR: cystic fibrosis transmembrane conductance regulator, HLA: human leukocyte antigen

\section{Case Report}

Figure 1 shows the family tree. The following individuals underwent detailed assessment: Case 1 (69-year-old woman, No. 1); Case 2 (No. 2), 2nd older sister of Case 1; sus-

${ }^{1}$ Department of Respiratory Medicine, National Hospital Organization, Ibaraki-Higashi National Hospital, Ibaraki and ${ }^{2}$ Department of Respiratory Diseases, Research Institute, International Medical Center of Japan, Tokyo

Received for publication October 15, 2009; Accepted for publication January 28, 2010

Correspondence to Dr. Masashi Matsuyama, brwck573@yahoo.co.jp 


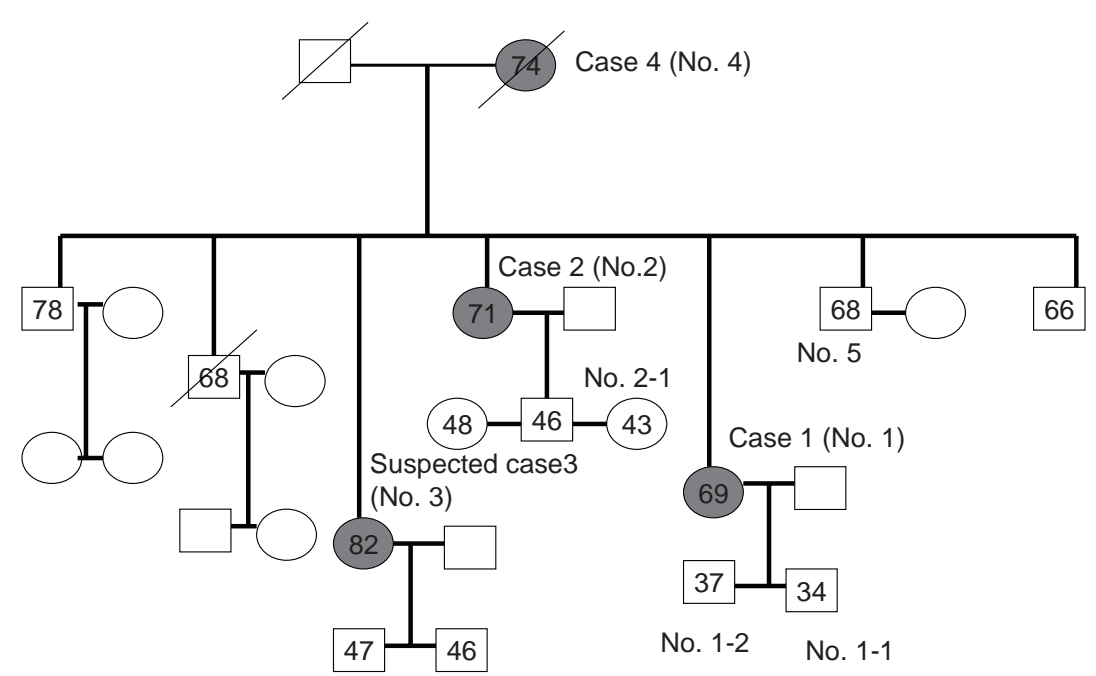

Figure 1. Family tree. Circles indicate females and squares refer to males. Numbers inside circles and squares indicate age (years) at the time of the present study. Gray symbols indicate those affected by pulmonary MAC, while white symbols refer to subjects unaffected by pulmonary MAC. Diagonal lines drawn through the symbols indicate deceased subjects.
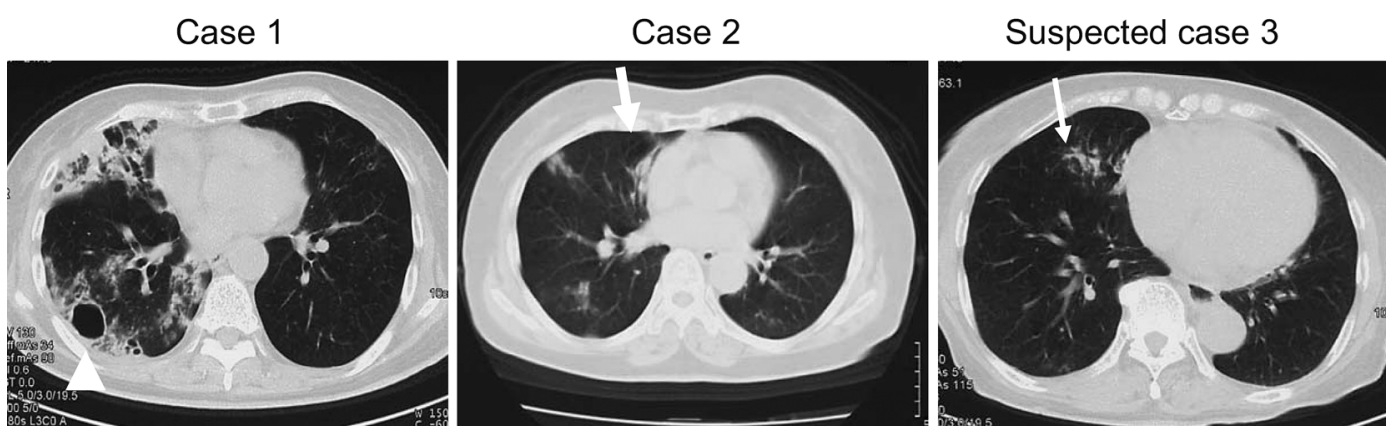

Figure 2. Computed tomography findings of Case 1, Case 2, and Case 3. Chest computed tomography (CT) scan demonstrates multiple, small, peripheral pulmonary nodules centred on the bronchovascular tree, cylindrical bronchiectasis, a cavitary lesion, and consolidations in Case 1 at the age of 69 years. The cavitary lesion, indicated by the arrowhead, resulted from expansion of the bronchiectatic lesion in Case 1. Multiple, small, peripheral, pulmonary nodules centred on the bronchovascular tree and cylindrical bronchiectasis are seen in Case 2, indicated by the arrow (at the age of 69 years). Nodular and centrilobular granular shadows are observed in Case 3, indicated by the thin arrow (at the age of 82 years). The CT scan findings of Case 1 are more severe than those of both Case 2 and Case 3.

pected Case 3 (No. 3), 3rd older sister of Case 1; younger brother of Case 1 (No. 5); two sons of Case 1 (No. 1-1 and No. 1-2); and a daughter of Case 2 (No. 2-1). Case 4 (No. 4), Case 1's mother, was deceased at the time of the study, but she had been diagnosed as having pulmonary MAC disease after menopause based on CT findings and sputum culture results.

Bacterial examination and chest CT findings confirmed nodular/bronchiectatic type pulmonary MAC disease in Cases 1 and 2 at 65 years of age. Chest CT showed nodular and centrilobular granular shadows in suspected Case 3 (Fig. 2); sputum cultures were negative, and bronchoscopic washing was not performed. It was thought that she might have pulmonary MAC disease associated with the same familial factors as her sisters and mother.
Delay in the time required for the taste of saccharin particles to be perceived was not observed in Case 1, Case 2, and suspected Case 3. Obstructive defects were not observed on pulmonary function testing, and elevated serum cold agglutinins were also not observed in any of the seven participating family members.

Standard commercial genetic mutation screening of the CFTR gene was performed in Case 1 (5); no known mutations and no novel variants were identified. The poly $\mathrm{T}$ polymorphisms in intron 8 (IVS8) of the CFTR gene were examined in all seven participating members (6). Three polymorphisms of the NRAMP1 gene, the $5^{\prime}(\mathrm{GT}) \mathrm{n}, \mathrm{D} 543 \mathrm{~N}$, and the 3'untranslated region TGTG insertion/deletion, were also genotyped in all seven family members (8). No significant differences between MAC cases and healthy members 
Table 1. Characteristics of Individual Members of This Family Line

\begin{tabular}{|c|c|c|c|c|c|c|c|c|}
\hline $\begin{array}{l}\text { Family } \\
\text { member } \\
\text { (No.) }\end{array}$ & $\begin{array}{r}\text { Age (at diagr } \\
\text {; years) }\end{array}$ & $\int^{\text {nosis }}$ Sex & Diagnosis & Complication & HLA-A & $\begin{array}{l}\text { CFTR } \\
\text { polyT }\end{array}$ & $\begin{array}{l}\text { NRAMP1 } \\
\text { D543N }\end{array}$ & $\begin{array}{c}\text { NRAMP1 } \\
\text { TGTG }\end{array}$ \\
\hline $\begin{array}{c}1 \\
\text { (case 1) }\end{array}$ & $69(65)$ & $\begin{array}{c}\mathrm{F} \\
\text { (post } \\
\text { memopausal) }\end{array}$ & $\begin{array}{l}\text { Pulmonary } \\
\text { M.intracellulare }\end{array}$ & $\begin{array}{c}\text { Sinusitis } \\
\text { DM } \\
\text { endometriosis }\end{array}$ & $26 / 26$ & $7 / 7$ & $\mathrm{G} / \mathrm{G}$ & ins/ins \\
\hline $1-1$ & 34 & M & - & - & $26 / 24$ & $7 / 7$ & $\mathrm{G} / \mathrm{G}$ & ins/ins \\
\hline $1-2$ & 37 & M & - & - & $26 / 24$ & $7 / 7$ & $\mathrm{G} / \mathrm{G}$ & ins/ins \\
\hline $\begin{array}{c}2 \\
\text { (case 2) }\end{array}$ & $71(65)$ & $\begin{array}{c}\mathrm{F} \\
\text { (post } \\
\text { menopausal) }\end{array}$ & $\begin{array}{l}\text { Pulmonary } \\
\text { M.avium }\end{array}$ & Sinusitis & $26 / 2$ & $7 / 7$ & $\mathrm{G} / \mathrm{G}$ & ins/ins \\
\hline $2-1$ & 43 & $\begin{array}{c}\mathrm{F} \\
\text { (pre } \\
\text { menopausal) }\end{array}$ & - & $\begin{array}{c}\text { Sinusitis } \\
\text { endometoriosis }\end{array}$ & $26 / 24$ & $7 / 7$ & $\mathrm{G} / \mathrm{G}$ & ins/ins \\
\hline $\begin{array}{c}3 \\
\text { (case 3) }\end{array}$ & $82(82)$ & $\begin{array}{c}\mathrm{F} \\
\text { (post } \\
\text { menopausal) }\end{array}$ & $\begin{array}{l}\text { Suspected } \\
\text { pulmonary } \\
\text { MAC }\end{array}$ & Sinusitis & $11 / 2$ & $7 / 7$ & $\mathrm{G} / \mathrm{G}$ & ins/ins \\
\hline $\begin{array}{c}4 \\
\text { (case 4) }\end{array}$ & $74(\mathrm{~N} / \mathrm{A})$ & $\begin{array}{c}\mathrm{F} \\
\text { (post } \\
\text { menopausal) }\end{array}$ & $\begin{array}{l}\text { Pulmonary } \\
\text { MAC }\end{array}$ & $\mathrm{N} / \mathrm{A}$ & $\mathrm{N} / \mathrm{A}$ & $\mathrm{N} / \mathrm{A}$ & $\mathrm{N} / \mathrm{A}$ & $\mathrm{N} / \mathrm{A}$ \\
\hline 5 & 68 & M & - & - & $26 / 2$ & $7 / 7$ & $\mathrm{G} / \mathrm{G}$ & ins/ins \\
\hline
\end{tabular}

HLA: human leukocyte antigen, CFTR: cystic fibrosis transmembrane conductance regulator, NRAMP1: natural resistance-associated macrophage protein one, MAC: Mycobacterium avium complex, DM: diabetes mellitus, N/A: not available, ins: insertion

were observed in the NRAMP1 and CFTR gene polymorphisms. HLA typing showed that HLA-A26 antigen was predominant.

The characteristics of individual family members are shown in Table 1. All female family members had sinusitis, and all patients were postmenopausal females at the time of diagnosis.

Case 1 received combination chemotherapy (clarithromycin (CAM) $600 \mathrm{mg} /$ day, ethambutol (EB) $750 \mathrm{mg} /$ day, rifampin (RFP) $450 \mathrm{mg} /$ day, and streptomycin (SM) $750 \mathrm{mg}$, 3 times a week for 3 months) because of productive cough. She continued to excrete MAC, and her CT findings worsened gradually despite adding levofloxacin (LVFX) $300 \mathrm{mg} /$ day to her medication (Fig. 2, CT findings at 69 years of age). Case 1 had a history of diabetes mellitus (DM). Combination chemotherapy, including CAM (600 mg/day), EB (750 mg/day), and RFP (300 mg/day), was prescribed in Case 2. Although the patient continued to have positive sputum cultures, her symptoms and chest X-ray and CT findings showed little change with combination therapy. Since suspected case 3 was asymptomatic, she remained untreated. Drug susceptibility testing for $M$. intracellulare showed an MIC of $0.5 \mu \mathrm{g} / \mathrm{mL}$ for CAM in Case 1; in Case 2, the MIC of $M$. avium for CAM was $2.0 \mu \mathrm{g} / \mathrm{mL}$. Case 1 had more severe symptoms and radiographic findings than Cases 2 and 3 (Fig. 2).
Abbreviation: MIC: minimal inhibitory concentration

\section{Discussion}

A familial study of the factors implicated in the development and exacerbation of pulmonary MAC disease, including testing for previously reported disease-susceptibility genes, was conducted in two pulmonary MAC cases, one suspected case, and four healthy members of this family.

Recurrent urinary tract infections occur in many postmenopausal women. In addition to epithelial atrophy, estrogen deficiency can increase vaginal $\mathrm{pH}$ and alter the vaginal flora, changes which may predispose to urinary tract infection (12). On the other hand, nodular-bronchiectatic type pulmonary MAC disease is well-known to occur after menopause. Estrogen may play also some role in resistance to MAC infection (13) due to its effects on various immune functions, such as macrophage activity, natural killer cell activity, and T cell-mediated immunity (13). Since all of the patients in this family were postmenopausal females, these factors might have been associated with pulmonary MAC disease onset.

In this family, all females had maxillary sinusitis, suggesting that they had sinobronchial syndrome. Hence, impaired mucociliary clearance may have been associated with pulmonary MAC disease in the females of this family. Major 
sinobronchial syndromes are classified into diffuse panbronchiolitis, primary ciliary dyskinesia, and cystic fibrosis. CFTR mutations appear to contribute to the susceptibility and pathogenesis of pulmonary nontuberculous mycobacteria (NTM) infection (5-7). CFTR protein is a cyclic adenosine monophosphatase-regulated chloride channel located in the apical membrane of epithelial cells. CFTR deletion impairs mucociliary clearance together with changes in the airway microenvironment, and it leads to a progressive cycle of infection and inflammation (6). Although CF incidence is very low in the Japanese population because of the rare possession of a typical delta F508 mutation of the CFTR gene (14), Mai et al reported associations between the IVS8 5T allele in the CFTR gene and pulmonary MAC infection in Japanese (6). However, the IVS8 5T alleles were not identified in this family. Also, the full CFTR gene analysis on the most severe patient (Case 1) revealed that neither known mutations nor novel variants were present. On the other hand, Ziedalski and Kim et al. reported that the prevalence of CFTR mutations in their pulmonary NTM cohort ranged from $36 \%$ to $50 \%$ in the United States $(5,7)$. Thus, the genetic background of pulmonary MAC disease may differ between Japanese and Caucasian populations.

In this family line, all seven participating members did not meet the diagnostic criteria for diffuse panbronchiolitis, because of the results of pulmonary function testing and the serum cold agglutinin results. As for primary ciliary dyskinesia, examinations of biopsies with electron microscopy were not performed, because the results of saccharin testing did not fulfill the diagnostic criteria for primary ciliary dyskinesia in Case 1, Case 2, and suspected Case 3.

The murine Nramp-1 determines susceptibility to intracellular pathogens. The human homologue, NRAMP1, might be involved in susceptibility to pulmonary MAC infection (8). All members of this family were homozygotes for major alleles of the D543N and TGTG insertion/deletion polymorphism of the NRAMP1 gene, which occurs in $70 \%$ to $80 \%$ of the Japanese population (8). As a result, the effect of these alleles in this family was unclear.

DM might be associated with deterioration of infection because of impaired cell-mediated immunity (15). Case 1, with DM, had more severe symptoms and radiographic findings than Cases 2 and 3, who did not have DM. Therefore, DM might contribute to the severity of pulmonary MAC disease.

HLA plays an important role in immune response; previous studies have shown that NTM lung disease is associated with HLA alleles (9-11). Kubo et al suggested that HLA A26 antigen might be associated with deterioration of pulmonary MAC infection (9). Case 1, with homozygously expressed HLA-A26, had more severe symptoms and radiographic findings than Case 2, with heterozygously expressed HLA-A26. Case 2 had more severe symptoms and radiographic findings than Case 3 without HLA-A26. Therefore, HLA-A26 might play a role in the deterioration of pulmonary MAC infection.

HLA class I antigens present peptides from inside the cell, including viral peptides if present. These peptides are produced from digested proteins that are broken down in the proteasomes. The peptides are also generally small polymers, about 9 amino acids in length. If foreign peptides are present on cells with HLA class I antigens, cells containing foreign proteins will be attacked by cytotoxic $\mathrm{T}$ lymphocytes. In general, HLA class I antigens are expressed on all nucleated cells, while HLA class II antigens are expressed on most immune system cells. HLA class I antigens are classified into A, B, and C. Therefore, it is speculated that certain peptides within the respiratory epithelium presented by HLA-A26 induce HLA-A26-restricted cytotoxic T lymphocytes, and this immune reaction is associated with deterioration of pulmonary MAC disease. Further studies detailing the role of HLA-A26 in the pathogenesis of pulmonary MAC disease are needed.

In conclusion, female sex and menopause might be associated with the onset of nodular/bronchiectatic type pulmonary MAC in this family. HLA-A26 antigen and DM might be involved in disease exacerbation. Thus, it is important to monitor the currently premenopausal daughters of Case 2 because of their similar backgrounds.

\section{References}

1. Griffith DE, Aksamit T, Brown-Elliott BA, et al. An official ATS/ IDSA statement: diagnosis, treatment, and prevention of nontuberculous mycobacterial diseases. Am J Respir Crit Care Med 175: 367-416, 2007.

2. Tanaka E, Kimoto T, Matsumoto H, et al. Familial pulmonary $M y$ cobacterium avium complex disease. Am J Respir Crit Care Med 161: 1643-1647, 2000.

3. Inoue T, Tanaka E, Sakuramoto M, et al. Three sisters of pulmonary Mycobacterium avium complex disease. Kansenshogaku Zasshi 79: 341-347, 2005 (in Japanese).

4. Sexton P, Harrison AC. Susceptibility to nontuberculous mycobacterial lung disease. Eur Respir J 31: 1322-1333, 2008.

5. Kim RD, Greenberg DE, Ehrmantraut ME, et al. Pulmonary nontuberculous mycobacterial disease: prospective study of a distinct preexisting syndrome. Am J Respir Crit Care Med 178: 1066-
1074, 2008.

6. Mai HN, Hijikata M, Inoue $\mathrm{Y}$, et al. Pulmonary Mycobacterium avium complex infection associated with the IVS8-T5 allele of the CFTR gene. Int J Tuberc Lung Dis 11: 808-813, 2007.

7. Ziedalski TM, Kao PN, Henig NR, et al. Prospective analysis of cystic fibrosis transmembrane regulator mutations in adults with bronchiectasis or pulmonary nontuberculous mycobacterial infection. Chest 130: 995-1002, 2006.

8. Tanaka G, Shojima J, Matsushita I, et al. Pulmonary Mycobacterium avium complex infection: association with NRAMP1 polymorphisms. Eur Respir J 30: 90-96, 2007.

9. Kubo K, Yamazaki Y, Hanaoka M, et al. Analysis of HLA antigens in Mycobacterium avium-intracellulare pulmonary infection. Am J Respir Crit Care Med 161: 1368-1371, 2000.

10. Takahashi M, Ishizaka $A$, Nakamura $H$, et al. Specific HLA in 
pulmonary MAC infection in a Japanese population. Am J Respir Crit Care Med 162: 316-318, 2000.

11. Um SW, Ki CS, Kwon OJ, et al. HLA antigens and nontuberculous mycobacterial lung disease in Korean patients. Lung 187: 136-140, 2009.

12. Caillouette JC, Sharp CF Jr, Zimmerman GJ, et al. Vaginal $\mathrm{pH}$ as a marker for bacterial pathogens and menopausal status. Am J Obstet Gynecol 176: 1270-1275, 1997.
13. Tsuyuguchi K, Suzuki K, Matsumoto H, et al. Effect of estrogen on Mycobacterium avium complex pulmonary infection in mice. Clin Exp Immunol 123: 428-434, 2001.

14. Yamashiro Y, Shimizu T, Oguchi $S$, et al. The estimated incidence of cystic fibrosis in Japan. J Pediatr Gastroenterol Nutr 24: 544$547,1997$.

15. Plouffe JF, Silva J Jr, Fekety R, et al. Cell-mediated immunity in diabetes mellitus. Infect Immun 21: 425-429, 1978.

(C) 2010 The Japanese Society of Internal Medicine http://www.naika.or.jp/imindex.html 